\title{
Metastatic gastric carcinoma from breast cancer mimicking primary linitis plastica: A case report
}

\author{
YASUMICHI YAGI $^{1}$, SHOZO SASAKI ${ }^{1}$, AKEMI YOSHIKAWA ${ }^{1}$, YUJI TSUKIOKA ${ }^{1}$, WATARU FUKUSHIMA ${ }^{1}$, \\ TAKASHI FUJIMURA ${ }^{1}$, HISASHI HIROSAWA ${ }^{1}$, RYOHEI IZUMI ${ }^{1}$ and KATSUHIKO SAITO ${ }^{2}$ \\ Departments of ${ }^{1}$ Surgery and ${ }^{2}$ Pathology, Toyama City Hospital, Toyama 939-8511, Japan
}

Received November 4, 2014; Accepted September 17, 2015

DOI: 10.3892/ol.2015.3788

\begin{abstract}
Metastases to the gastrointestinal tract rarely occur in breast cancer except in invasive lobular carcinoma. The present study reports a rare case of metastatic gastric cancer from invasive ductal carcinoma (IDC) of the breast mimicking primary gastric linitis plastica. A 51-year-old premenopausal female, who had a history of partial mastectomy for right breast cancer at the age of 40, was referred to Toyama City Hospital (Toyoma, Japan) for an endoscopic diagnosis of gastric linitis plastica. Abdominal computed tomography (CT) revealed left hydronephrosis, while peritoneal metastasis and malignant ascites were not detected. Chest CT detected a left lung tumor, which had invaded the left upper bronchus. Biopsy specimens were obtained and the histopathological findings on both the gastric tumor and lung tumor demonstrated poorly differentiated adenocarcinoma, whereas the histology of the original breast cancer was IDC with a solid-tubular type. Immunohistochemistry revealed that the biopsied specimens of the gastric and lung tumors were positive for estrogen receptor $(\mathrm{ER})$, progesterone receptor $(\mathrm{PgR})$ and negative for human epithelial growth factor receptor-2 (HER2). These molecular characteristics indicated the case was metastatic gastric carcinoma from the breast cancer with lung metastasis, since the statuses of ER, PgR and HER2 were concordant with those of the original breast cancer. However, the possibility of primary gastric cancer could not be completely ruled out. Therefore, a total gastrectomy was performed for the purpose of both diagnosis and treatment. Pathological examination of the resected specimen provided a definite diagnosis of multiple metastatic gastric carcinomas from the breast. To the best of our knowledge, metastatic gastric cancer derived from the breast presenting as linitis plastica 11 years following the surgical removal of IDC has not been described previously.
\end{abstract}

Correspondence to: Dr Yasumichi Yagi, Department of Surgery, Toyama City Hospital, 2-1 Imaizumi, Toyama 939-8511, Japan E-mail: y-yagi@live.jp

Key words: gastric metastasis, breast cancer, linitis plastica

\section{Introduction}

In breast cancer, the common sites of metastasis are the lung, bones, liver and brain (1) and metastases to the gastrointestinal tract rarely occur. Among the histological subtypes, which include ductal carcinoma, lobular carcinoma, mucinous carcinoma, apocrine carcinoma and spindle cell carcinoma, invasive lobular carcinoma (ILC) is well known to metastasize to the gastrointestinal tract, gynecological organs, peritoneum, and retroperitoneum in comparison with invasive ductal carcinoma (IDC) (2). Although patients with gastric metastasis from breast cancer are rarely encountered, the recognition and awareness of this metastatic pattern is important in making an accurate diagnosis and providing appropriate treatment.

The present study reports a rare case of metastatic gastric cancer from IDC of breast, which was initially diagnosed as primary gastric linitis plastica.

\section{Case report}

In July 2013, a 51-year-old premenopausal woman, who had a history of partial mastectomy for right breast cancer at the age of 40, was referred to Toyama City Hospital (Toyoma, Japan) for a diagnosis of gastric linitis plastica. She presented with upper abdominal pain and a complaint of body weight loss (-10 kg/6 months). Following partial mastectomy, which was performed in July 2002, the patient received administration of tamoxifen (20 mg, daily) as adjuvant hormone therapy for 3 years.

Endoscopy revealed a Borrmann type 4 tumor (3) on the greater curvature of the upper stomach (Fig. 1A). Gastrography indicated scirrhous gastric cancer localized in the upper stomach (Fig. 2). Enhanced abdominal computed tomography (CT) revealed increased wall thickness of the stomach and left hydronephrosis. Nodal metastasis and liver metastasis were not detected. Peritoneal metastasis and malignant ascites were also not detected. Abdominal magnetic resonance imaging revealed hydronephrosis with stenosis of the uretovesical junction, indicating retroperitoneal metastasis. Chest CT detected a left lung tumor that had invaded the left upper bronchus. Bronchial fiberscopy revealed left upper bronchial stenosis by the extrinsic tumor (Fig. 1B). The biopsy specimens of the stomach demonstrated poorly differentiated adenocarcinoma, 

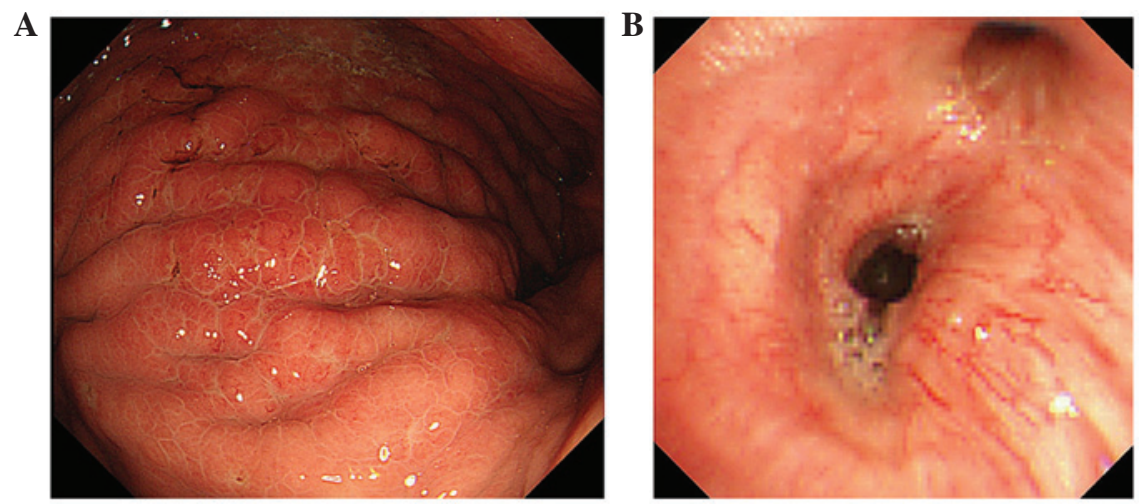

Figure 1. Endoscopic findings. (A) A type 4 tumor was present on the greater curvature of the upper stomach, accompanied by edematous and erosive changes. (B) Bronchial fiberscopy revealed left upper bronchial stenosis by the extrinsic tumor.

while those of the lung tumor also revealed poorly differentiated adenocarcinoma, suggestive of a metastatic lung tumor (Fig. 3). Levels of tumor markers were within normal limits, as follows: Carcinoembryonic antigen (CEA), $1.7 \mathrm{ng} / \mathrm{ml}$ (normal, $<5.0 \mathrm{ng} / \mathrm{ml}$ ); carbohydrate antigen (CA) $19-9,6.2 \mathrm{ng} / \mathrm{ml}$ (normal, <37.0 ng/ml); CA125, $10.7 \mathrm{U} / \mathrm{ml}$ (normal, <35.0 U/ml); and CA15-3, $12.6 \mathrm{U} / \mathrm{ml}$ (normal, $<28.0 \mathrm{U} / \mathrm{ml}$ ).

Immunohistochemistry (IHC) revealed that the biopsy specimens of the gastric and lung tumors were estrogen receptor (ER) positive/progesterone receptor $(\mathrm{PgR})$ positive/human epithelial growth factor receptor-2 (HER2) negative (Fig. 4). IHC also indicated positivity for cytokeratin (CK) 7 and negativity for CK20 in both tumors. By contrast, the histology of the original breast cancer was IDC with a solid-tubular type (Fig. 3), which was $3.5 \mathrm{~cm}$, ER positive, $\mathrm{PgR}$ positive, HER 2 negative, and without nodal involvement. Thereafter, these molecular characteristics indicated metastatic gastric carcinoma from the breast cancer with lung metastasis. In addition, left hydronephrosis was probably caused by the retroperitoneal metastasis from the breast origin. However, the possibility of primary gastric cancer could not be completely ruled out by the endoscopic biopsied materials, even in combination with IHC.

When comparing the prognosis of recurrent breast cancer at a later stage without a history of receiving chemotherapy with that of primary gastric linitis plastica, the gastric malignancy would be more life-threatening in the case of primary gastric cancer. The therapeutic strategy was explained to the patient, who decided to undergo a surgical resection of the gastric tumor for local control of the gastric lesion. Subsequently, a total gastrectomy with splenectomy was performed after confirming the absence of macroscopic peritoneal dissemination and no evidence of cancer cells on intraoperative peritoneal lavage cytology. The postoperative period was uneventful. Macroscopic findings of the resected stomach revealed multiple gastric lesions (Fig. 5). Pathological examination of the resected specimens provided a definite diagnosis of multiple metastatic gastric carcinomas from IDC of the breast. Based on the diagnosis, administration of tamoxifen was restarted as endocrine therapy. After a one-year follow-up period, the patient was asymptomatic and regular examinations have not demonstrated a relapse of the disease.

Written informed consent for the present study was obtained from the patient.

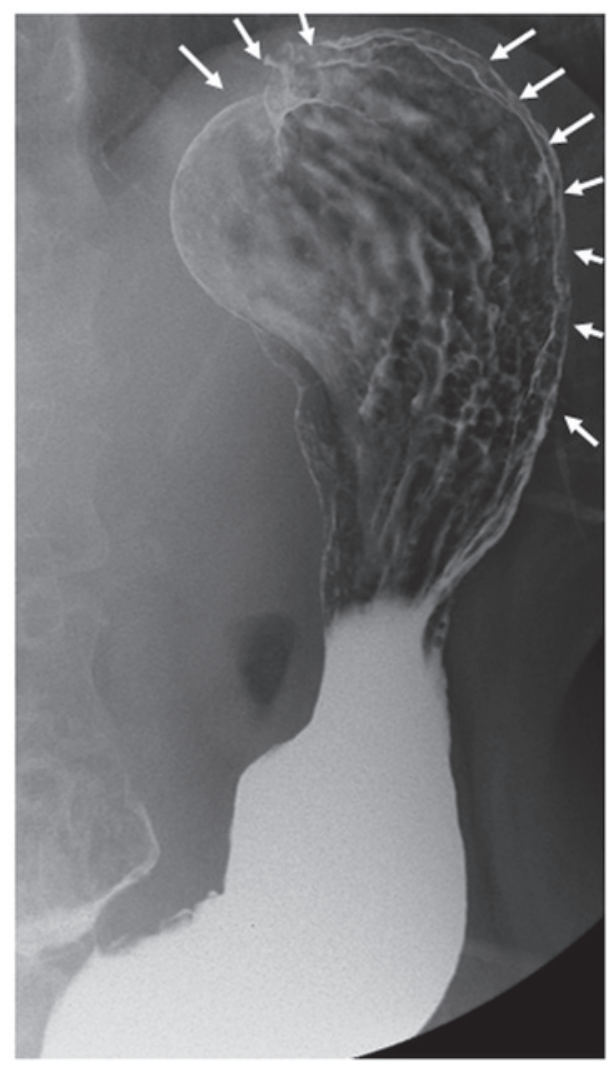

Figure 2. Gastrographic findings. Barium meal showed sclerotic change localized in the upper stomach (white arrows).

\section{Discussion}

Gastric metastases are predominantly a result of malignant melanoma, followed by lung and breast cancer $(4,5)$. Metastatic lesions due to hematogenous or lymphatic spread usually implant in the submucosal layer of the stomach, appearing as one or multiple submucosal nodules, sometimes accompanied by ulcerative change and large masses (6). Hence, localized lesions tend to exhibit submucosal appearance and diffused lesions may appear to be scirrhous gastric cancer on endoscopical findings (7). Since metastatic lesions of stomach cancer often invade the gastric wall without mucosal destruction, endoscopic biopsy often presents as a false negative (8). Therefore, in certain cases, deep biopsies are recommended 
A

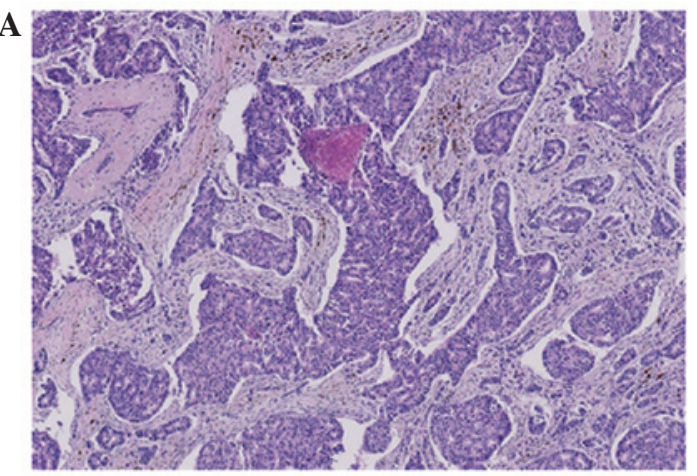

C

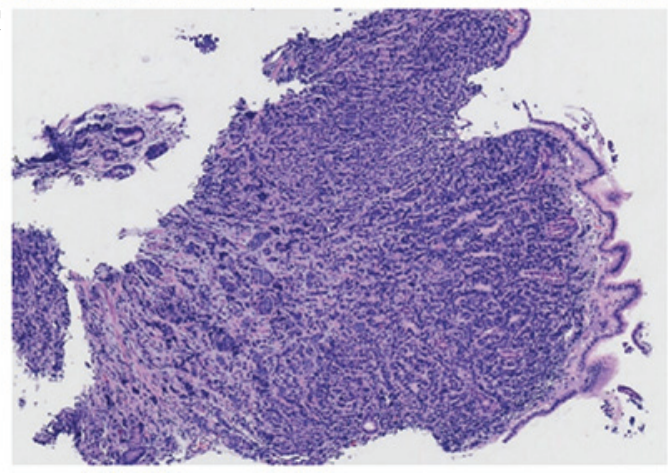

B

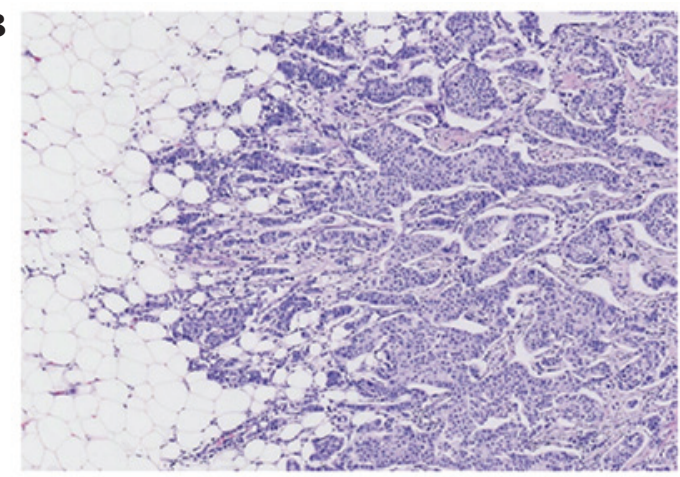

D

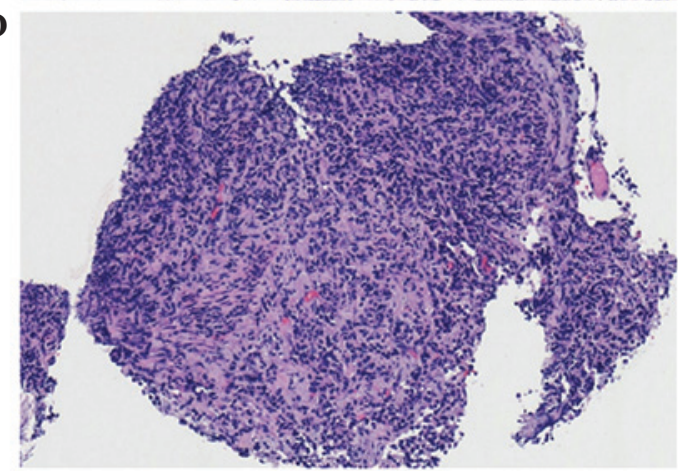

Figure 3. Histological findings. (A) The original breast cancer exhibited invasive ductal carcinoma (IDC) with a solid-tubular type (HE staining, x100). (B) At the marginal site of the original breast cancer, tumor tissue exhibited undifferentiated morphology with stromal invasion (HE staining, $\mathrm{x} 40$ ). (C) Biopsied specimen of the gastric lesion showed poorly differentiated adenocarcinoma (HE staining, x40). (D) Biopsied specimen of the lung lesion showed poorly differentiated adenocarcinoma (HE staining, $\mathrm{x} 40$ ).
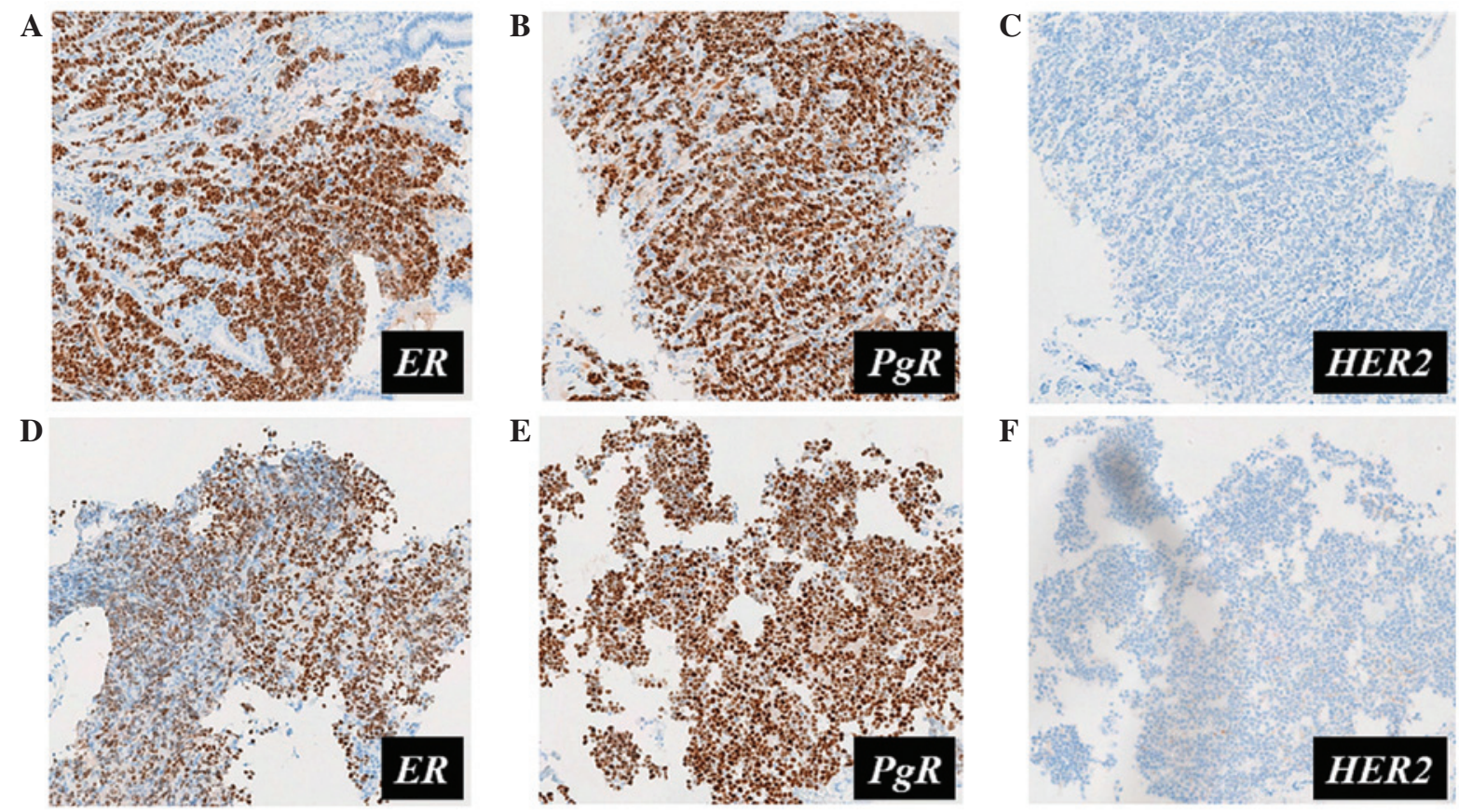

Figure 4. Status of receptor expression as assessed by immunohistochemistry of biopsied (A-C) gastric and (D-F) lung lesions. . Statuses of the receptors on the stomach and lung lesions were ER positive, PgR positive, and HER2 negative, in accordance with those of the original breast cancer (x40). ER, estrogen receptor; PgR, progesterone receptor; HER2, human epithelial growth factor receptor-2.

to obtain sufficient materials for histological diagnosis and special staining. Madeya et al (9) reported that $73 \%$ of patients with gastric metastases had diffuse intramural infiltration presenting as linitis plastica. As for breast cancer, ILC has been reported to be the most common type that metastasizes to the stomach mimicking gastric linitis plastica (10). However, gastric metastasis from IDC of breast presenting linitis plastic has not been described previously. In the present case, histological examination revealed IDC. Although the possibility of ILC was considered for the original breast cancer, no evidence 


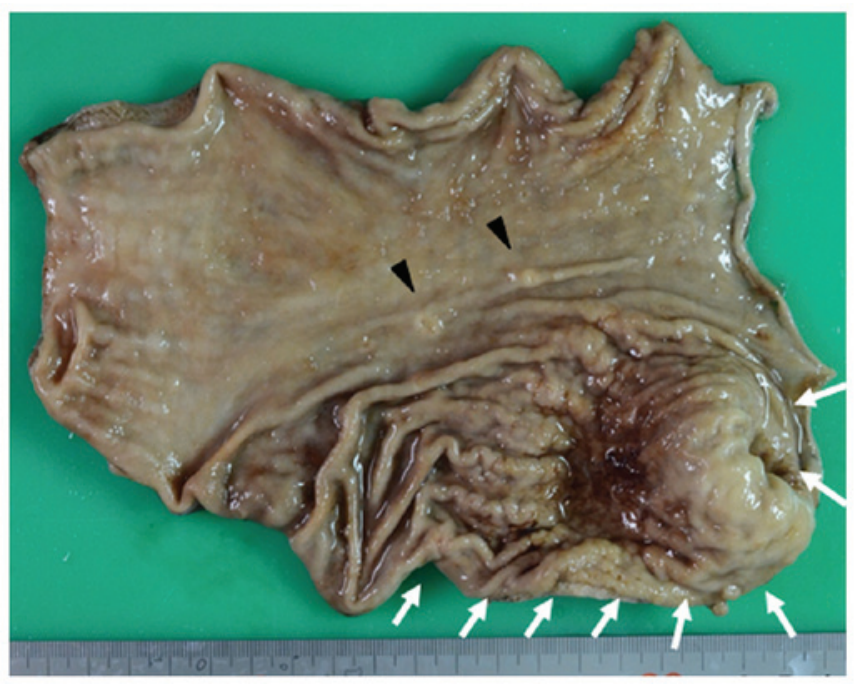

Figure 5. Macroscopic findings of the resected stomach. Type 4 tumor was present on the greater curvature of the upper stomach (white arrows). Apart from the main lesion, two verrucoid lesions, which were overlooked on endoscopic examination, were detected on the middle stomach (black arrowheads). These multiple lesions, including the Type 4 tumor, lacked continuity with each other. The histological examination of each lesion demonstrated identical findings: Poorly differentiated adenocarcinoma located mainly on the submucosal layer.

of ILC was demonstrated because E-cadherin expression was not reduced when assessed by IHC.

Metastatic gastric linitis plastica is clinically indistinguishable from primary gastric linitis plastica (5), as was observed in the present case. As a supplemental diagnostic tool, IHC is often used for exploration of molecular characteristics. Since about $80 \%$ of human breast tumors express hormone receptors $(10,11), \mathrm{ER}$ and $\mathrm{PgR}$ have been used as reliable markers to determine the breast origin. By contrast, it is well known that $\mathrm{ER}, \mathrm{PgR}$, and HER 2 expression may be altered at the metastatic site over the course of disease progression (12). Previous reports also have demonstrated that the discordance of ER and PgR status between primary breast cancer and those metastases is 15-40\%, and most of the discordances included loss of ER and PgR expression $(13,14)$. While expression of the hormone receptors plays a major role in progression of breast cancer, it is little known that primary gastric carcinomas also express ER and PgR in some cases; according to Matsui et al (15), the positivity rates of $\mathrm{ER}$ and $\mathrm{PgR}$ are 32 and $12 \%$, respectively in gastric cancer patients. Tokunaga et al (16) also described that primary gastric carcinoma expressed ER in $26.6 \%$ and $\mathrm{PgR}$ in $20.6 \%$. In summary, it is concluded that regardless of whether a gastric lesion derives from the stomach or breast, discordance of ER and PgR status is likely to occur regardless. Therefore, ER or $\mathrm{PgR}$ status is not always a suitable diagnostic marker to confirm that a tumor originated from the breast. However, concordance of these hormone receptor expression levels between primary and secondary lesions may be useful for a differential diagnosis. And their combination with other supplemental diagnostic markers would be valuable to improve the accuracy of diagnosis. Apart from the expression of hormone receptors, the CK7+/CK20-group may also be used to characterize a primary breast tumor: $33 \%$ of primary gastric cancers exhibit a $\mathrm{CK}^{+} / \mathrm{CK}^{2} 0^{-}$expression phenotype (17). Mammoglobin has been also described as a valuable specific marker of breast origin. Its expression rate has been reported to be $47.8-80 \%$ in primary and metastatic breast tumors (18-20). In contrast to ER and $\mathrm{PgR}$ expression, the expression of mammoglobin does not change at the metastatic site (21).

A clinical image of a metastatic gastric tumor is important in addition to histological examination for a diagnosis. The first and foremost priority is to establish whether there are metastatic lesions in other organs. In the present case, gastric metastasis was the first presentation of the disease, though the other asymptomatic metastases were also complicated. If lesions within other organs exist, they should be differentiated from metastases of the breast origin. Secondly, gastric metastasis often presents as multiple lesions and tends to be located in the middle or upper third of the stomach (22). In the present case, a retrospective observation of the endoscopic images enabled the detection of another overlooked lesion in the middle of the stomach (Fig. 5). Comparison with the histology of the second lesion's biopsy made the diagnosis of metastatic gastric cancer more reliable. Thereafter, at an endoscopic examination, information on a patient's clinical history, especially for ILC, would be useful to determine whether the gastric lesion derived from the breast or stomach. In cases where there is a history of breast cancer, comparison with the original histological slides of the primary breast cancer should be made to differentiate gastric metastasis from primary gastric cancer.

Distinguishing between primary and metastatic gastric carcinoma in patients with a history of breast cancer is important because the treatment completely differs depending on whether the primary lesion derives from the stomach or breast. In the case of primary gastric cancer, surgical resection is the most effective treatment for patients without distant and peritoneal metastasis. In regards to breast cancer, because metastasis of breast cancer is a systemic disease, metastatic gastric cancer is indicated for systemic therapy with chemotherapy and hormone therapy. In atypical cases of metastatic gastric cancer affecting general condition, including uncontrollable gastrointestinal bleeding and obstruction, gastrectomy or gastrojejunostomy may be indicated as palliative surgery.

Metastatic gastric carcinoma is relatively rare, accounting for $2-18 \%$ of breast cancer patients (23). Considering the high incidence of breast cancer and low incidence of gastric linitis plastica, clinicians should not exclude the possibility of a secondary gastric lesion from the breast origin in any woman who has been diagnosed with gastric linitis plastica. Particularly in a patient with a history of ILC, endoscopic examinations should be performed carefully (24). If metastasis to the stomach is definitively diagnosed, unnecessary surgery may be avoided.

In conclusion, it is important to make an accurate diagnosis in combination with IHC for metastatic gastric carcinoma. To the best of our knowledge, metastatic gastric carcinoma derived from the breast presenting as linitis plastica 11 years, as was observed in the present study, following the surgical removal of IDC has not been described previously.

\section{References}

1. Cummings MC, Simpson PT, Reid LE, Jayanthan J, Skerman J, Song S, McCart Reed AE, Kutasovic JR, Morey AL, Marquart L, et al: Metastatic progression of breast cancer: Insights from 50 years of autopsies. J Pathol 232: 23-31, 2014. 
2. Borst MJ and Ingold JA: Metastatic patterns of invasive lobular versus invasive ductal carcinoma of the breast. Surgery 114: 637-641, 1993.

3. Kitamura K, Beppu R, Anai H, Ikejiri K, Yakabe S, Sugimachi K and Saku M: Clinicopathologic study of patients with Borrmann type IV gastric carcinoma. J Surg Oncol 58: 112-117, 1995.

4. Campoli PM, Ejima FH, Cardoso DM, Silva OQ, Santana Filho JB, Queiroz Barreto PA, Machado MM, Mota ED, Araujo Filho JA, Alencar Rde C and Mota OM: Metastatic cancer to the stomach. Gastric Cancer 9: 19-25, 2006.

5. Oda, Kondo H, Yamao T, Saito D, Ono H, Gotoda T, Yamaguchi H, Yoshida S and Shimoda T: Metastatic tumors to the stomach: Analysis of 54 patients diagnosed at endoscopy and 347 autopsy cases. Endoscopy 33: 507-510, 2001.

6. Menuck LS and Amberg JR: Metastatic disease involving the stomach. Am J Dig Dis 20: 903-913, 1975.

7. Levine MS, Kong V, Rubesin SE, Laufer I and Herlinger H: Scirrhous carcinoma of the stomach: Radiologic and endoscopic diagnosis. Radiology 175: 151-154, 1990

8. Pectasides D, Psyrri A, Pliarchopoulou K, Floros T, Papaxoinis G, Skondra M, Papatsibas G, Macheras A, Athanasas G, Arapantoni-Datioti P and Economopoulos T: Gastric metastases originating from breast cancer: Report of 8 cases and review of the literature. Anticancer Res 29: 4759-4763, 2009.

9. Madeya S and Börsch G: Gastrointestinal metastases of breast carcinoma. Gastrointest Endosc 39: 103-104, 1993.

10. Almubarak MM, Laé M, Cacheux W, de Cremoux P, Pierga JY, Reyal F, Bennett SP, Falcou MC, Salmon RJ, Baranger B and Mariani P: Gastric metastasis of breast cancer: A single centre retrospective study. Dig Liver Dis 43: 823-827, 2011.

11. de Decker L, Campone M, Retornaz F, Berrut G, Kabeshova A, Molinié $\mathrm{F}$ and Beauchet $\mathrm{O}$ : Association between oestrogens receptor expressions in breast cancer and comorbidities: A cross-sectional, population-based study. PLoS One 9. e98127, 2014.

12. Amir E, Clemons M, Purdie CA, Miller N, Quinlan P, Geddie W, Coleman RE, Freedman OC, Jordan LB and Thompson AM: Tissue confirmation of disease recurrence in breast cancer patients: Pooled analysis of multi-centre, multi-disciplinary prospective studies. Cancer Treat Rev 38: 708-714, 2012.
13. Simmons C, Miller N, Geddie W, Gianfelice D, Oldfield M, Dranitsaris G and Clemons MJ: Does confirmatory tumor biopsy alter the management of breast cancer patients with distant metastases? Ann Oncol 20: 1499-1504, 2009.

14. Amir E, Miller N, Geddie W, Freedman O, Kassam F, Simmons C, Oldfield M, Dranitsaris G, Tomlinson G, Laupacis A, et al: Prospective study evaluating the impact of tissue confirmation of metastatic disease in patients with breast cancer. J Clin Oncol 30: 587-592, 2012.

15. Matsui M, Kojima O, Kawakami S, Uehara Y and Takahashi T: The prognosis of patients with gastric cancer possessing sex hormone receptors. Surg Today 22: 421-425, 1992.

16. Tokunaga A, Nishi K, Matsukura N, Tanaka N, Onda M, Shirota A, Asano G and Hayashi K: Estrogen and progesterone receptors in gastric cancer. Cancer 57: 1376-1379, 1986.

17. Tot T: Cytokeratins 20 and 7 as biomarkers: Usefulness in discriminating primary from metastatic adenocarcinoma. Eur J Cancer 38: 758-763, 2002.

18. Luo MH, Huang YH, Ni YB, Tsang JY, Chan SK, Shao MM and Tse GM: Expression of mammaglobin and gross cystic disease fluid protein-15 in breast carcinomas. Hum Pathol 44: 1241-1250, 2013.

19. Galvis-Jiménez JM, Curtidor H, Patarroyo MA, Monterrey P and Ramírez-Clavijo SR: Mammaglobin peptide as a novel biomarker for breast cancer detection. Cancer Biol Ther 14: 327-332, 2013.

20. Chia SY, Thike AA, Cheok PY and Tan PH: Utility of mammaglobin and gross cystic disease fluid protein-15 (GCDFP-15) in confirming a breast origin for recurrent tumors. Breast 19: 355-359, 2010.

21. Watson MA and Fleming TP: Mammaglobin, a mammary-specific member of the uteroglobin gene family, is overexpressed in human breast cancer. Cancer Res 56: 860-865, 1996.

22. De Palma GD, Masone S, Rega M, Simeoli I, Donisi M, Addeo P, Iannone L, Pilone V and Persico G: Metastatic tumors to the stomach: Clinical and endoscopic features. World J Gastroenterol 12: 7326-7328, 2006.

23. Jones GE, Strauss DC, Forshaw MJ, Deere H, Mahedeva U and Mason RC: Breast cancer metastasis to the stomach may mimic primary gastric cancer: Report of two cases and review of literature. World J Surg Oncol 5: 75, 2007.

24. Tan L, Piao Y, Liu Z, Han T, Song F, Gao F, Han Y and Xie X: Breast cancer metastasis to the stomach confirmed using gastroscopy: A case report. Oncol Lett 8: 1205-1207, 2014. 